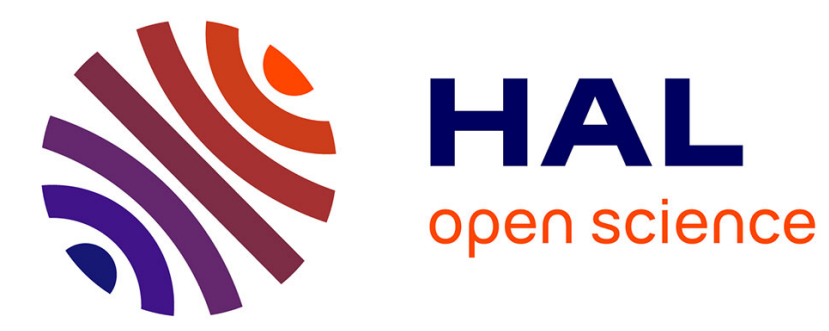

\title{
Experimental study of the spectral properties of near-field and far-field jet noise
}

Christophe Bogey, Sébastien Barré, Vincent Fleury, Christophe Bailly, Daniel

Juvé

\section{- To cite this version:}

Christophe Bogey, Sébastien Barré, Vincent Fleury, Christophe Bailly, Daniel Juvé. Experimental study of the spectral properties of near-field and far-field jet noise. International Journal of Aeroacoustics, 2007, 6 (2), pp.73-92. 10.1260/147547207781041868 . hal-00272250

\section{HAL Id: hal-00272250 \\ https://hal.science/hal-00272250}

Submitted on 11 Apr 2016

HAL is a multi-disciplinary open access archive for the deposit and dissemination of scientific research documents, whether they are published or not. The documents may come from teaching and research institutions in France or abroad, or from public or private research centers.
L'archive ouverte pluridisciplinaire HAL, est destinée au dépôt et à la diffusion de documents scientifiques de niveau recherche, publiés ou non, émanant des établissements d'enseignement et de recherche français ou étrangers, des laboratoires publics ou privés. 


\title{
Experimental study of the spectral properties of near-field and far-field jet noise
}

\author{
Christophe Bogey ${ }^{\dagger}$, Sébastien Barrē ${ }^{\ddagger}$, Vincent Fleury ${ }^{\dagger \dagger}$, \\ Christophe Bailly $¥ \ddagger$ and Daniel Juvé \\ Laboratoire de Mécanique des Fluides et d'Acoustique, UMR CNRS 5509 , \\ Ecole Centrale de Lyon, 69134 Ecully Cedex, France
}

\begin{abstract}
The near and far pressure fields generated by round, isothermal and cold jets of diameter $D=38 \mathrm{~mm}$ with Mach numbers varying over the range $0.6 \leq \mathrm{M}_{j} \leq 1.6$ are investigated experimentally, and characterized in terms of sound spectra and levels. Properties of near-field jet noise, obtained in particular at 7.5 diameters from the jet centerline, are documented. They differ appreciably from properties of far-field noise, and form a database that can be used for the validation of the acoustic fields determined by compressible Navier-Stokes computations. The near pressure fields originating from simulations can thus be directly compared, without resorting to extrapolation methods which might lead to uncertainties in the far pressure fields. In the present paper, sound source localizations are also carried out from the near-field pressure signals. The experiments provide in addition far-field results evaluated at 52 diameters from the nozzle exit, in good agreement with the data of the literature. The classical dependence of jet noise features with the emission angle is observed. The level and frequency scalings of the pressure spectra obtained for subsonic jets in the sideline and downstream directions are also studied. For small radiation angles, the narrow-banded sound spectra measured are found to scale as the Strouhal number, whereas, as previously noted by Zaman \& Yu [1], the one-third octave spectra seem to scale as the Helmholtz number.
\end{abstract}

†CNRS Research Scientist, christophe.bogey@ec-lyon.fr

${ }^{\ddagger} \mathrm{PhD}$., sebastien.barre@ dassault-aviation.com, current address: Dassault Aviation, 78 quai Marcel Dassault, Cedex 300, 92552 Saint Cloud Cedex, France

††PhD., vincent.fleury@onera.fr, current address: Office National d'Etudes et de Recherches Aérospatiales, 29 avenue de la Division Leclerc, BP72, 92322 Chatillon Cedex, France

‡¥Professor at Ecole Centrale de Lyon, christophe.bailly@ec-lyon.fr

IProfessor at Ecole Centrale de Lyon, daniel.juve@ec-lyon.fr 


\section{INTRODUCTION}

Experiments and theoretical studies have led over the last fifty years to considerable progress in the prediction and understanding of subsonic and supersonic jet noise $[2,3]$. New perspectives are now offered by the methods of Computational AeroAcoustics (CAA), which have made significant advances over the last few years, reported in the recent review of Wang et al. [4] and illustrated for instance by the jet simulations of the present authors $[5,6,7,8]$. The computational results however appear to depend appreciably on several parameters such as the numerical algorithm, the inflow and boundary conditions, and the turbulence modelling. Careful validations have therefore to be performed to demonstrate that jet noise can be calculated with high fidelity. There is also a need for unambiguous experimental data. Unfortunately results might vary between different experiments, notably because of acoustic contamination by extraneous noise or of the use of one-third octave spectra as pointed out respectively by Viswanathan [9] and by Zaman \& Yu [1].

An accurate description of near-field jet noise can be in particular useful for the validation of simulation results. Indeed in CAA, due to computer limitations, only the near-field pressure is generally calculated directly. The far-field pressure is then classically obtained using extrapolation methods, which allow the radiated sound to be evaluated from quantities on an arbitrary control surface surrounding the acoustic sources. These methods are based on simplified sets of the flow motion equations, or on integral formulations as it is the case for the Kirchhoff method and for the porous Ffowcs-Williams Hawkings equations, see the review of Lyrintzis [10]. For the prediction of jet noise, they have been for instance applied by Rahier et al. [11], Uzun et al. [12], Andersson et al. [13] and Barré et al. [7]. The sound field predicted by this way is unfortunately likely to depend on the type of method and on the position of the control surface, as shown, among others, by Brentner \& Farassat [14], Rahier et al. [11], and Gloerfelt et al. [15]. Refraction effects outside the control surface might also be neglected [10]. To avoid the uncertainties resulting from these extrapolation methods, an alternative is to compare directly the near-field numerical results with corresponding experimental data. Such near-field data can enable to display features of jet noise, and to give information on the sound sources. Illustrations are provided in Yu \& Dosanjh [16] and Troutt \& McLaughlin [17] for supersonic jets, and in Zaman [18] and Ukeiley \& Ponton [19] for subsonic jets. From near-field data, noise source localization can in addition be carried out, as in Narayanan et al. [20]. Regarding aerodynamic features, pressure signals estimated in the vicinity of jets can get an insight into the large-scale structures of the turbulent flow, as discussed in Arndt et al. [21] and in Coiffet et al. [22].

To identify jet noise components, far-field measurements are however required. With this aim in view, it is interesting to consider the variations of the far pressure field with the polar angle or with the Mach number [2,3]. The scaling laws of jet noise spectra are nevertheless still a matter of debate. This is particularly the case for the scaling of the frequency peaks obtained in the downstream direction for subsonic jets. Using one-third octaves in Lush [23], Ahuja \& Bushell [24] and Tanna [25], the noise spectra at small radiation angles seem to scale as the Helmholtz number $\mathrm{Hm}=f D / c_{\infty}$ ( $f$ is the frequency, $D$ 
the jet diameter and $c_{\infty}$ the ambient speed of sound). Zaman \& Yu [1] demonstrated later that this Helmholtz scaling is an artifact of the use of one-third octaves, resulting in a shift of the peak frequency. Using narrow bands, the experimental data and findings are however confusing. The spectra indeed appear to scale as the Strouhal number $\mathrm{St}=$ $f D / U_{j}$ in Mollo-Christensen et al. [26], as the Helmholtz number in Gaeta \& Ahuja [27], and as the Helmholtz number times a Doppler factor, i.e. with $\mathrm{Hm} \times\left(1-\mathrm{M}_{c} \cos \theta\right)$ in Zaman \& $\mathrm{Yu}[1]\left(U_{j}\right.$ is the jet velocity, $\mathrm{M}_{c}$ a convection Mach number, $\theta$ the polar angle with respect to the jet direction). This point has to be clarified in order to strengthen the identification and modelling of jet noise components, performed for instance in Tam et al. [28] and in Goldstein \& Leib [29].

In the present work, experiments are carried out in the anechoic wind tunnel of the Centre Acoustique at Ecole Centrale de Lyon, in order to characterize the near and far pressure fields for isothermal and cold jets at Mach numbers over the range $0.6 \leq \mathrm{M}_{j} \leq 1.6$. The jet diameter is $D=38 \mathrm{~mm}$, yielding Reynolds numbers $\operatorname{Re}_{D} \geq 5 \times 10^{5}$. The objective is twofold. The first one is to complement the near-field jet noise data available in the literature, and to provide a database for the validation of the acoustic results provided by unsteady compressible simulations. The second one is to shed light on some features of jet acoustic radiation with the aim of better understanding and modelling jet noise. Spectral properties of jet noise will be described in the near field between $r=7.5 \mathrm{D}$ and $r=20 D$ from the jet centerline ( $r$ is the distance from the jet axis), and in the far field at a distance of $52 D$ from the nozzle exit. The results will be compared to experimental data of the literature when it is possible. Sound source localizations will be carried out from the near-field pressure signals. The level and frequency scalings of the far-field pressure spectra obtained for subsonic jets in the sideline and downstream directions will be also investigated.

The paper is organized as follows. In section 2, the experimental set-up and instrumentation are presented, and the parameters of the jets investigated are defined. The properties obtained for the near pressure field and for the far pressure field are shown in section 3. Concluding remarks are finally drawn in section 4.

\section{EXPERIMENTAL SET-UP AND JET SPECIFICATIONS}

\subsection{Experimental set-up}

The present experiments are carried out in the high-speed anechoic wind tunnel $(10.3 \times$ $8 \times 7.6 \mathrm{~m}^{3}$, cut-off frequency of $100 \mathrm{~Hz}$ ) of the Centre Acoustique located at Ecole Centrale de Lyon [30]. An airflow facility designed to provide continuous subsonic and supersonic jets [31] is used. The air supply system is composed of a screw compressor of power $350 \mathrm{~kW}$ with a mass flow rate of $Q=1 \mathrm{~kg} . \mathrm{s}^{-1}$, of an air dryer (power $12 \mathrm{~kW}$ ) and of a set of resistances of total power $64 \mathrm{~kW}$ providing a stagnation temperature up to $T_{t}=500 \mathrm{~K}$. A nozzle of exit diameter $D=38 \mathrm{~mm}$ is mounted on the converging section of the cylindrical settling chamber. The area ratio and the axial length of the final contraction are respectively $5.6 / 1$ and $10 \mathrm{~cm}$. The thickness of the nozzle lip is $2 \mathrm{~mm}$. Low levels of velocity fluctuations are observed on the centerline at the nozzle exit, and the jet Mach number varies by less than 3\% during the experiments. Jets compensated 


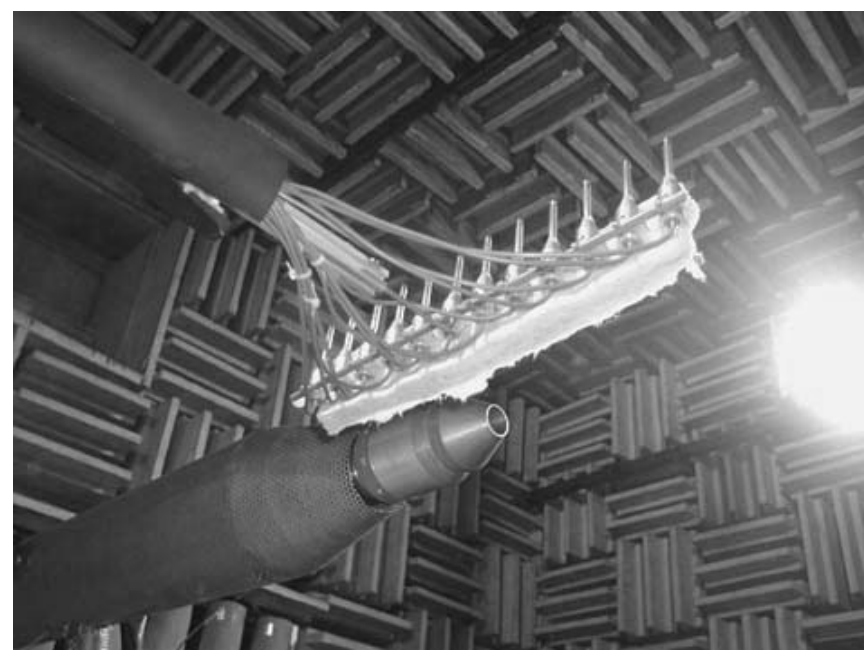

Figure 1: Experimental set-up used for the investigation of near-field jet noise.

in temperature, yielding $T_{j}=T_{\infty}$, at Mach numbers $\mathrm{M}_{\mathrm{j}}=U_{j} / c_{\infty}$ over the range $0.6-1.1$ are investigated $\left(T_{j}\right.$ and $U_{j}$ are the nozzle-exit temperature and velocity, $T_{\infty}$ and $c_{\infty}$ are the ambient temperature and speed of sound). A cold jet at $\mathrm{M}_{\mathrm{j}}=1.6$ is also considered. The jet Reynolds numbers $\operatorname{Re}_{D}=U_{j} D / v$, where $v$ is the kinematic molecular viscosity, are thus between $5.3 \times 10^{5}$ and $2 \times 10^{6}$. For such Reynolds numbers, according to the works of Zaman [32], these jets can be expected to be initially turbulent. Finally note that for the isothermal jets, the flow Mach number is also the acoustic Mach number.

\subsection{Near-field measurements}

Near-field measurements are performed for three isothermal jets at Mach numbers $M_{j}=0.6$, 0.9 and 1.1, and for a cold jet at $\mathrm{M}_{\mathrm{j}}=1.6$, as reported in table 1 . The pressure field is investigated using a linear array of 12 microphones one-fourth inch B\&K axially spaced every diameter $D$, and mounted at grazing incidence in order to minimize the influence of the microphone directivity, as illustrated in figure 1 . The microphone boom is wrapped with acoustic lining in order to minimize reflections, and the protection grid of the microphones is removed. In this way, pressure signals are recorded along lines parallel to the jet axis, at the radial positions $r=7.5 D, 10 D, 15 D$ and $20 D$. At $r=7.5 D$ and $10 D$, the lines extend from $x=0$ up to $x=23 D$ for the subsonic jets $(x$ is the axial distance from the nozzle exit), but from $x=-12 D$ up to $x=23 D$ for the supersonic jets. At $r=15 D$ and $20 D$, they start at $x=0$ and end at $x=35 D$ for the four jets. The acoustic data are acquired with a Hewlett-Packard 35652B set in a Paragon multi-channel spectrum analyser, with a frequency resolution of $3 \mathrm{~Hz}$. Power Spectral Density (PSD) is estimated over the frequency range $3 \mathrm{~Hz}-77 \mathrm{kHz}$ using 450 samples. 
Table 1: Characteristics of the jets considered for the investigation of near-field jet noise

\begin{tabular}{ccccccc}
$\mathbf{M}_{\mathbf{j}}$ & $\boldsymbol{T}_{\infty}(\mathbf{K})$ & $\boldsymbol{P}_{\infty}(\mathbf{b a r})$ & $\boldsymbol{T}_{\mathbf{j}}(\mathbf{K})$ & $\boldsymbol{P}_{\mathbf{j}}(\mathbf{b a r})$ & $\boldsymbol{U}_{\mathbf{j}}\left(\mathbf{m . s}{ }^{-\mathbf{1}}\right)$ & $\mathbf{R e}_{\boldsymbol{D}}$ \\
\hline 0.6 & 282 & 0.986 & 282 & 0.987 & 202 & $5.3 \times 10^{5}$ \\
0.9 & 283 & 0.982 & 283 & 0.980 & 304 & $7.9 \times 10^{5}$ \\
1.1 & 282 & 0.986 & 282 & 0.987 & 370 & $9.7 \times 10^{5}$ \\
1.6 & 282 & 0.987 & 220 & 0.986 & 473 & $1.9 \times 10^{6}$
\end{tabular}

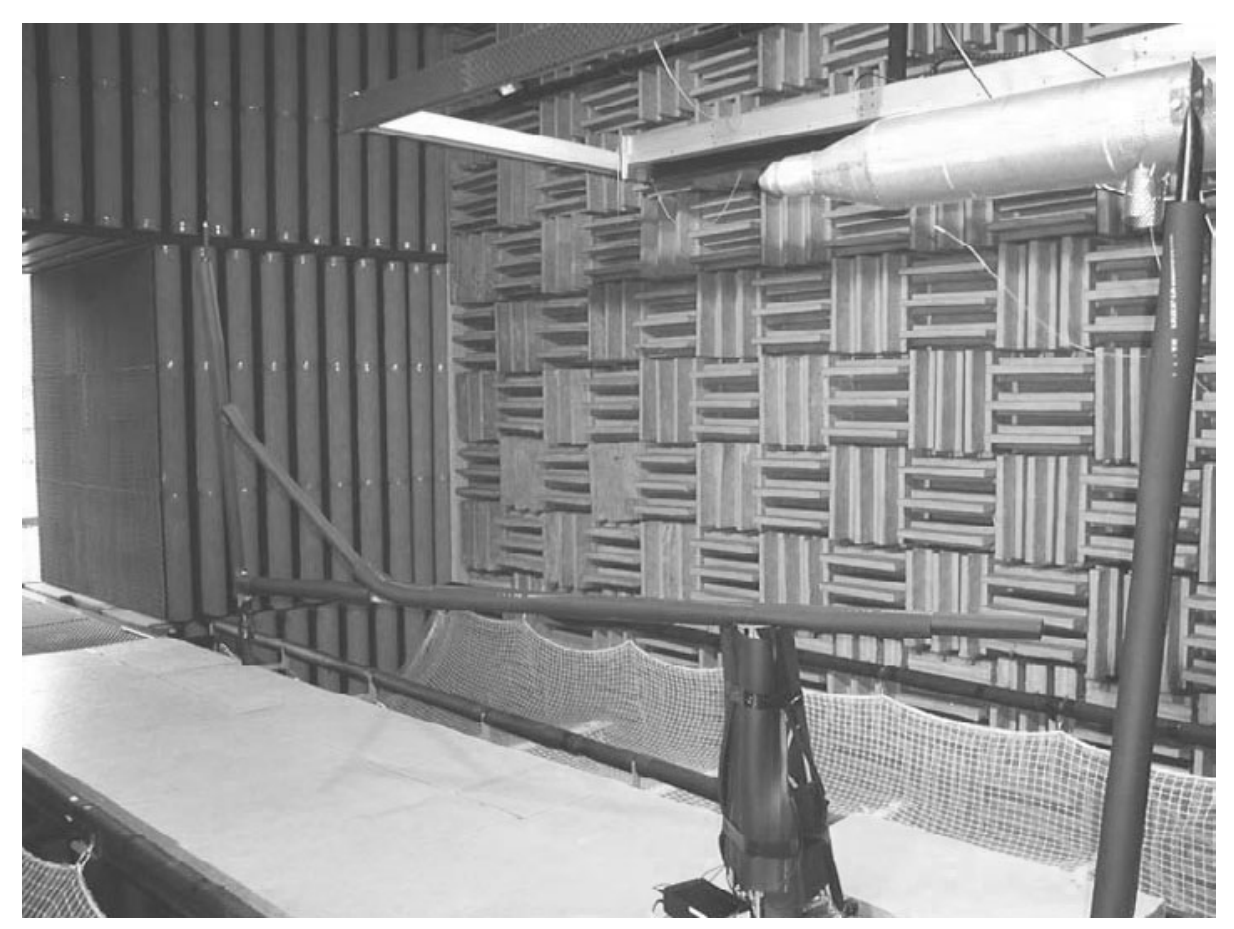

Figure 2: Experimental set-up used for the investigation of far-field jet noise.

\subsection{Far-field measurements}

Far-field measurements are done for five isothermal jets at Mach numbers $\mathrm{M}_{\mathrm{j}}=0.6$, $0.75,0.9,0.98$ and 1.1, and for a cold jet at $\mathrm{M}_{\mathrm{j}}=1.6$. Nominal parameters of the jets are provided in table 2. The pressure field is studied using a one-fourth inch B\&K (Bruel \& Kjaer 4939, with BK 2804 Power Supply) microphone located on an arc of radius $2 \mathrm{~m}$, or $52.6 \mathrm{D}$, centered at the nozzle exit, which is shown in figure 2 . The properties of the radiated noise are obtained for polar angles between $\theta=10^{\circ}$ and $\theta=150^{\circ}$ with respect 
Table 2: Characteristics of the jets considered for the investigation of far-field jet noise

\begin{tabular}{lcccccc}
$\mathbf{M}_{\mathbf{j}}$ & $\boldsymbol{T}_{\infty}(\mathbf{K})$ & $\boldsymbol{P}_{\infty}(\mathbf{b a r})$ & $\boldsymbol{T}_{\mathbf{j}}(\mathbf{K})$ & $\boldsymbol{P}_{\mathbf{j}}(\mathbf{b a r})$ & $\boldsymbol{U}_{\mathbf{j}}\left(\mathbf{m . s}^{\mathbf{- 1}}\right)$ & $\mathbf{R e}_{\boldsymbol{D}}$ \\
\hline 0.6 & 284 & 0.967 & 284 & 0.964 & 203 & $5.3 \times 10^{5}$ \\
0.75 & 282 & 0.967 & 282 & 0.966 & 252 & $6.6 \times 10^{5}$ \\
0.9 & 286 & 0.970 & 286 & 0.971 & 306 & $7.8 \times 10^{5}$ \\
0.98 & 282 & 0.967 & 282 & 0.967 & 330 & $8.7 \times 10^{5}$ \\
1.1 & 282 & 0.981 & 282 & 0.985 & 370 & $9.7 \times 10^{5}$ \\
1.6 & 281 & 0.982 & 220 & 0.983 & 478 & $2.0 \times 10^{6}$
\end{tabular}

to the jet direction. As previously for the near-field experiments, the microphone boom is wrapped with acoustic lining, and the protection grid of the microphone is removed. The acoustic data are acquired with a Hewlett-Packard 35652B set in a Paragon multichannel spectrum analyser, with a frequency resolution of $3 \mathrm{~Hz}$. Power Spectral Density (PSD) is estimated over the frequency range $3 \mathrm{~Hz}-77 \mathrm{kHz}$ using 400 samples, and is corrected from the effects of the atmospheric absorption of sound [33, 34].

\section{RESULTS}

\subsection{Near-field jet noise}

To illustrate the near-field measurements, the pressure levels obtained for the jet at $\mathrm{M}_{\mathrm{j}}=0.9$ are represented in figure 3 using iso-contours over the whole study region. Slight irregularities are observed at $x=12 D$ and at $x=24 D$, at the axial locations corresponding to the junction zones between two adjacent sets of data given by the twelve-microphone boom. The reason for this has unfortunately not been identified, and we can only suggest a calibration issue for the last microphone of the boom. The radiation patterns compare however well with experimental data, provided for instance by Zaman [18] and by Ukeiley \& Ponton [19], for subsonic round jets. The overall sound levels of figure 3(a) indicate in particular that the jet radiates noise preferentially in the downstream direction, at small polar angles with respect to the jet direction. In order to display the influence of frequency on the radiation directivity, the sound levels filtered at Strouhal numbers $\mathrm{St}=f D / U_{j}=0.2,0.5$, and 1 are presented in figures $3(\mathrm{~b}), 3(\mathrm{~b})$ and 3(c), respectively ( $\mathrm{f}$ is the frequency). The peak levels are highest at $\mathrm{St}=0.2$, and appear to decrease with the Strouhal number, in agreement with previous studies [18, 19]. The well-known variations of the jet directivity with the frequency are also observed: with increasing Strouhal number, the dominant angle of radiation is larger, and the noise sources move towards the upstream direction, and become closer to the jet nozzle.

The overall sound pressure levels obtained along the line $r=7.5 D$ are plotted in figure 4(a) over $0 \leq x \leq 20 D$ for the subsonic jets, and in figure 4(b) over $-10 D \leq x \leq 20 D$ for the supersonic jets. Such sound levels, just outside the jet flow, may be particularly useful for the validation of numerical results, because the line $r=7.5 \mathrm{D}$ can usually be included in the computational domain of Navier-Stokes simulations using current 
(a)

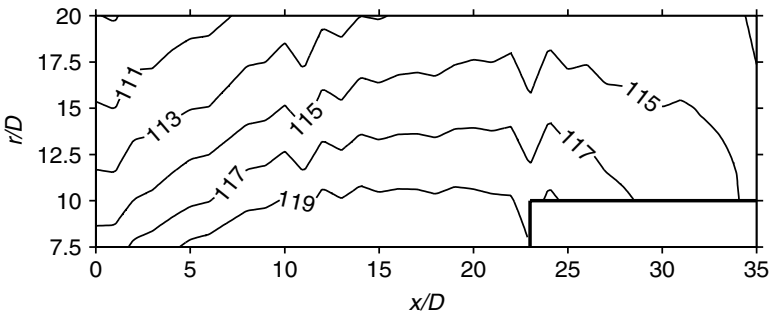

(b)

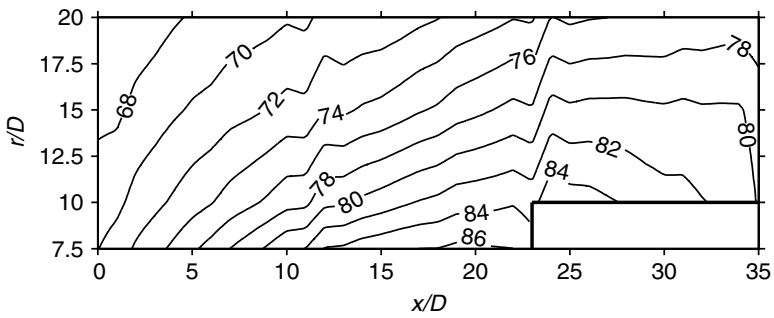

(c)

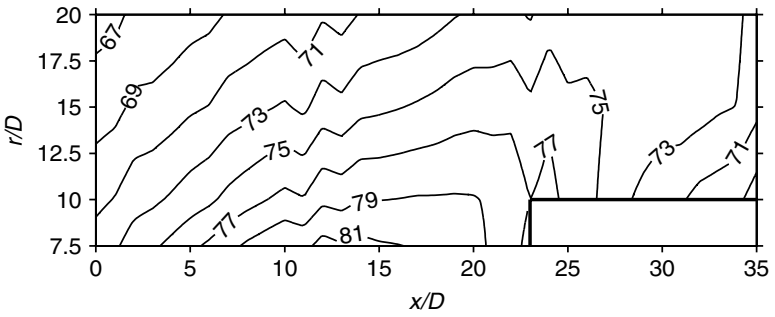

(d)

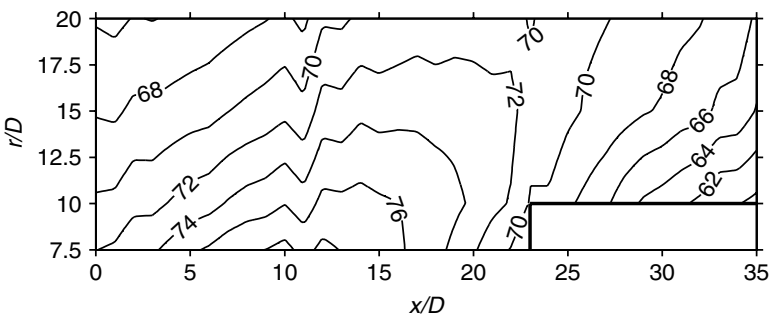

Figure 3: Near-field sound pressure levels obtained for the jet at $\mathrm{M}_{\mathrm{j}}=0.9$. Contours represented every $2 \mathrm{~dB}$ of: (a) overall sound pressure levels; (b) levels filtered at Strouhal number $\mathrm{St}=0.2$; (c) levels filtered at $\mathrm{St}=0.5$; (d) levels filtered at $\mathrm{St}=1$.

computational resources. They have been for instance compared recently in Barré et al. [7] with the noise levels evaluated directly by compressible Large-Eddy Simulations for isothermal jets at $\mathrm{M}_{\mathrm{j}}=0.9$ with different nozzle-exit conditions. In this way, the additional noise generated by jets with initially laminar conditions has been exhibited. In figure 4 , in agreement with previous experiments $[16,17,18,19]$, the sound levels increase with the 
(a)

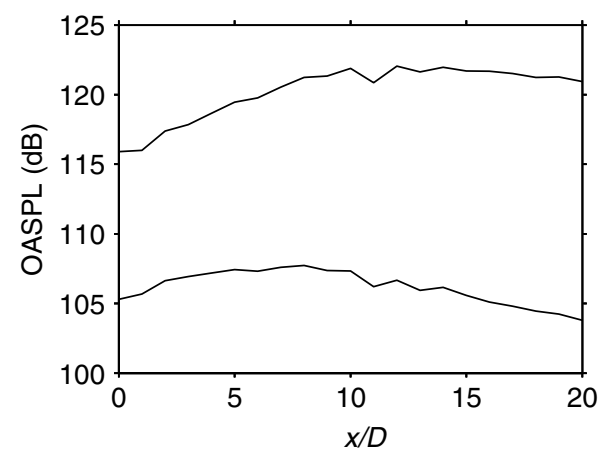

(b)

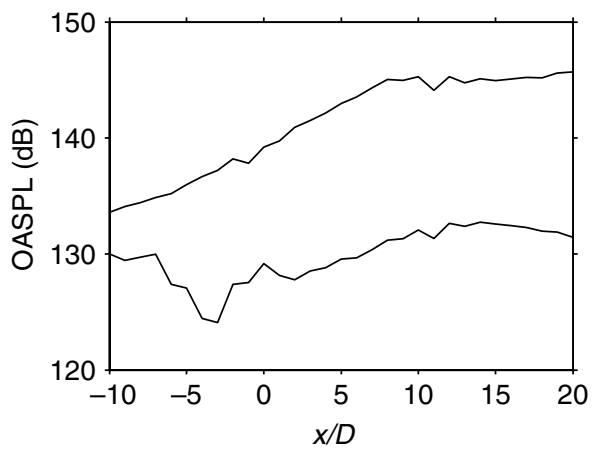

Figure 4: Overall sound pressure levels obtained along the line $r=7.5 D$ : (a) for the subsonic jets at Mach numbers $M_{j}=0.6$ and 0.9 (from bottom to top), (b) for the supersonic jets at $\mathrm{M}_{\mathrm{j}}=1.1$ and 1.6 (from bottom to top).

jet velocity, and they are higher for large $x / D$, except for the jet at $\mathrm{M}_{\mathrm{j}}=1.1$. For this supersonic jet, two lobes seem to be observed, one in the direction perpendicular to the jet nozzle, near $x=0$, and another in the upstream direction for $x \leq-5 D$. This behaviour suggests the generation of screech tones within the jet $[2,8,35]$.

The spectral properties of near-field noise are now investigated. The pressure spectra measured at the axial locations $x=0,5 D, 10 D, 15 D$, and $20 D$ along the line $r=7.5 D$ are presented in figure 5 for the four jets considered, as functions of the Strouhal number, for $0.05 \leq \mathrm{St} \leq 6.4$. The modifications of the shape of the spectra with the axial position $x / D$ are significant. They are expected to be connected with the variations of subsonic and supersonic jet noise with the radiation angles $[2,3]$.

For the subsonic jets in figures 5(a) and 5(b), as the axial position increases, the pressure levels are higher, and the spectra become narrower and peak at lower Strouhal numbers. These changes are clearly illustrated by the black and cyan curves obtained respectively at the locations $x=0$ and $x=20 D$. For the $\mathrm{M}_{\mathrm{j}}=0.9$ jet, the peak Strouhal number is thus for instance $\mathrm{St}=0.7$ at $x=0$, but $\mathrm{St}=0.13$ at $x=20 D$. Contributions of aerodynamic pressure to the near-field spectra are visible for the Mach 0.6 jet. They are indicated by the pressure-level increase noticed in figure 5(a) at low Strouhal numbers, especially at the downstream location $x=20 D$ (cyan curve). The aerodynamic and acoustic components seem however distinct in terms of frequency. The acoustic components appear in particular to be predominant for Strouhal numbers $\mathrm{St} \geq 0.08$ at $\mathrm{M}_{\mathrm{j}}=0.6$, and for $\mathrm{St} \geq 0.05$ at $\mathrm{M}_{\mathrm{j}}=0.9$, which is similar with the experimental observations of Arndt et al. [21] who showed that the near-field pressure fluctuations are acoustic for wave numbers $k r>2.0$, yielding, at $r=7.5 D$, St $>0.071$ for the Mach 0.6 jet and St $>0.047$ for the Mach 0.9 jet. Note in addition that the sound levels presented in figures 3 and 4 have been calculated by integrating only the acoustical part of the pressure spectra. 
(a)

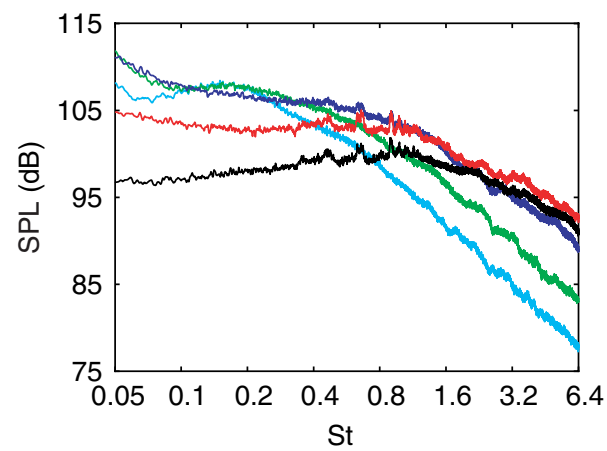

(c)

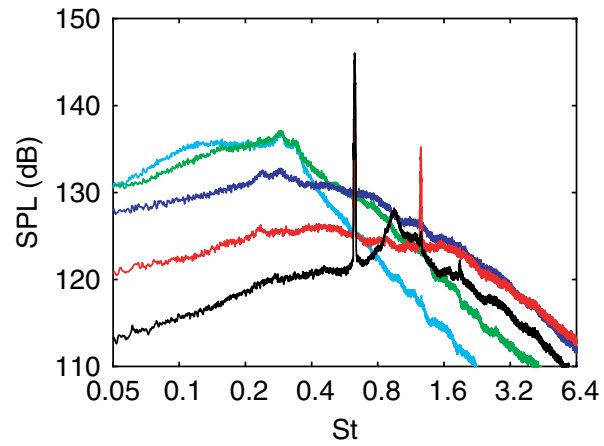

(b)

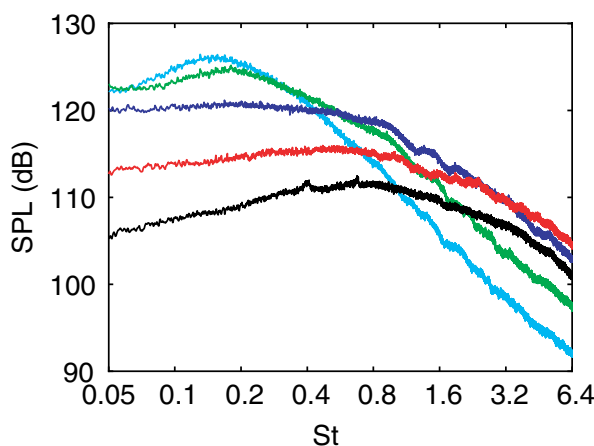

(d)

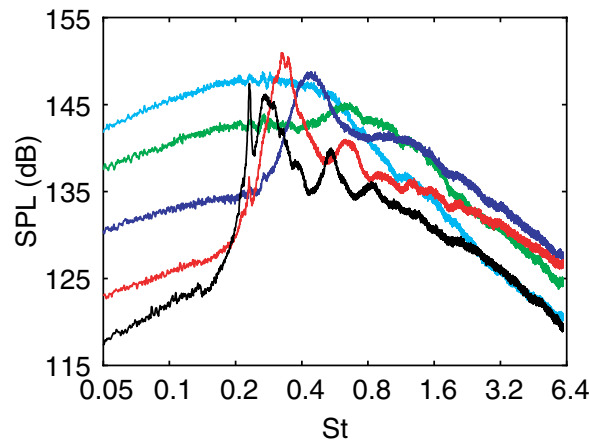

Figure 5: Sound pressure spectra obtained along the line $r=7.5 D$ at: $-x=0$, $-x=5 D,-x=10 D,-x=15 D$, and $-x=20 D$. Jets at Mach numbers: (a) $\mathrm{M}_{\mathrm{j}}=0.6$, (b) $\mathrm{M}_{\mathrm{j}}=0.9$, (c) $\mathrm{M}_{\mathrm{j}}=1.1$, and (d) $\mathrm{M}_{\mathrm{j}}=1.6$.

In the spectra of the supersonic jets in figures 5(c) and 5(d), discrete screech tones emerge, especially for $x \leq 5 D$. The Strouhal numbers of the fundamental tones are equal to $\mathrm{St}=0.63$ at $\mathrm{M}_{\mathrm{j}}=1.1$, and $\mathrm{St}=0.23$ at $\mathrm{M}_{\mathrm{j}}=1.6$, which agrees well with the predictions of Tam's model [2], providing $\mathrm{St}=0.66$ and $\mathrm{St}=0.20$. Properties of far-field screech radiation [35] are also observed in the present near-field spectra. The first harmonic is for instance particularly significant at $x=5 D$ perpendicular to the jet flow, whereas the fundamental screech tone is the highest more upstream at $x=0$. The screech radiation is also stronger in the $\mathrm{M}_{\mathrm{j}}=1.1$ jet than in the $\mathrm{M}_{\mathrm{j}}=1.6$ jet. In the latter case, significant components of broadband shock-associated noise are observed for frequencies just higher than the fundamental screech tone.

The pressure spectra obtained in the direction perpendicular to the jet nozzle exit, at $x=0$ and $r=7.5 D$, are specifically presented in figure 6 for the four jets. Screech tones and broadband shock-associated noise are in particular well distinguishable in the supersonic jets. 


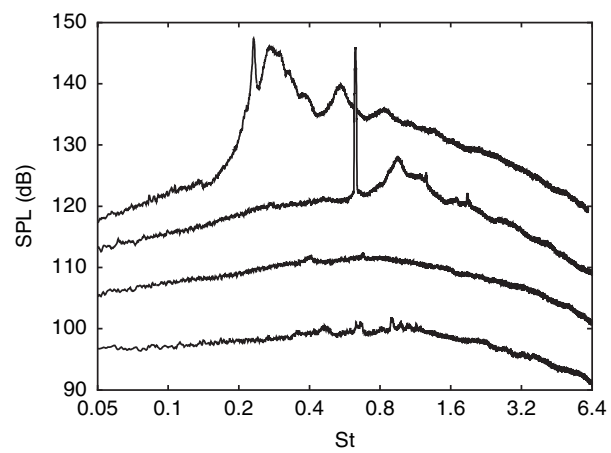

Figure 6: Sound pressure spectra obtained at $x=0$ and $r=7.5 D$ for the jets at Mach numbers $\mathrm{M}_{\mathrm{j}}=0.6,0.9,1.1$ and 1.6 , from bottom to top.

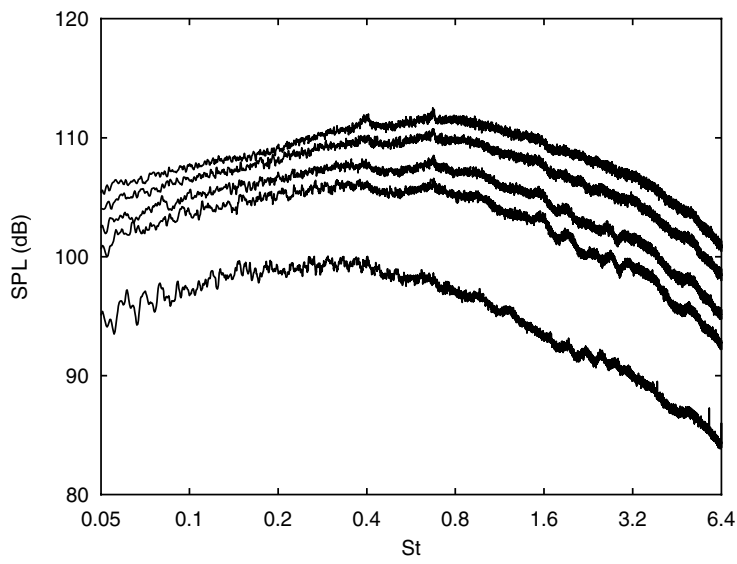

Figure 7: Sound pressure spectra obtained for the jet at $\mathrm{M}_{\mathrm{j}}=0.9$, at $x=0$ and, from top to bottom: $r=7.5 D, r=10 D, r=15 D, r=20 D$ and $r=52 D$.

The variations with the radial distance of the spectra obtained for the Mach 0.9 jet at $x=0$ in the direction perpendicular to the nozzle exit are shown in figure 7, where the pressure spectra are plotted for radial positions ranging from $\mathrm{r}=7.5 \mathrm{D}$ up to $r=52 \mathrm{D}$. For larger radial distances from the jet, the frequency peaks move towards lower Strouhal numbers, from $\mathrm{St}=0.7$ at $r=7.5 \mathrm{D}$ down to $\mathrm{St}=0.3$ in far-field at $r=52 \mathrm{D}$. As expected, properties of near-field noise are appreciably different from properties of farfield noise, which supports the need of accurate near-field measurements for the validation of direct simulation results. 
(a)

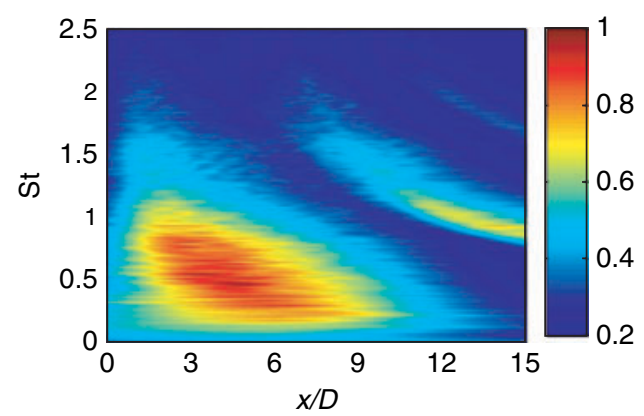

(b)

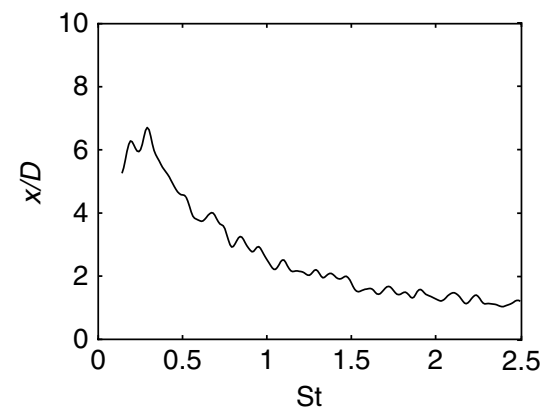

Figure 8: Localization of sound sources in the jet at $\mathrm{M}_{\mathrm{j}}=0.9$ using an array of 12 microphones located between $x=0$ and $x=11 D$ along the line $r=7.5 D$ : (a) normalized intensity of acoustic sources along the jet axis and (b) location of the intensity maximum, as a function of the Strouhal number St.

The near-field pressure signals can be used for source localization along the jet axis. Among the number of source localization methods, described for instance in the review of Elias [36], the method implemented by Zoppellari and Juvé [31, 37] was chosen. Based on a microphone array located in the near field, it consists of calculating the theoretical source distribution along the jet axis which provides the cross-spectrum matrix closest to the matrix measured between the sensors of the array. In the present work, sound source localization is carried out in the subsonic jet at $\mathrm{M}_{\mathrm{j}}=0.9$, using an array of 12 microphones located between $x=0$ and $x=11 D$ along the line $r=7.5 D$. The source distribution pattern obtained is presented in figure 8(a) as a function of the Strouhal number. The trends typically observed for the mixing noise in subsonic cold jets, see for example in Narayanan et al. [20], are found: high-frequency sources, associated with small turbulent structures, are located near the nozzle exit, whereas low-frequency sources are located far downstream. Secondary sources also appear for high frequencies farther downstream but they are due to spatial aliasing. Finally, the variations of the location of the noise source maximum with the Strouhal number are shown in figure 8(b). The noise radiated at Strouhal numbers St around 0.25, i.e. at frequencies corresponding to the dominant components in subsonic jet noise, classically appears to be generated near the end of the potential core [38], around $x=6 D$, whereas the noise at higher Strouhal numbers originates in the vicinity of the nozzle exit, presumably in the developing shear layers.

\subsection{Far-field jet noise}

The overall sound pressure levels evaluated in far-field for the different jets of table 2 are presented in figure 9(a), as functions of the polar angle with respect to the jet direction. The jets radiate predominantly in the downstream direction, with level peaks for about $\theta=25^{\circ}$. For $\theta<25^{\circ}$, effects of refraction of sound waves by the flows are 
(a)

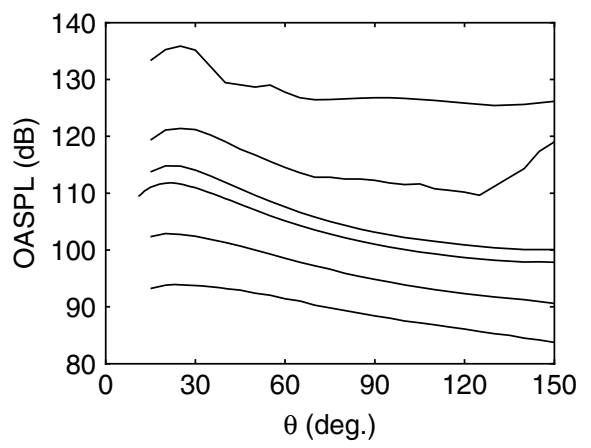

(b)

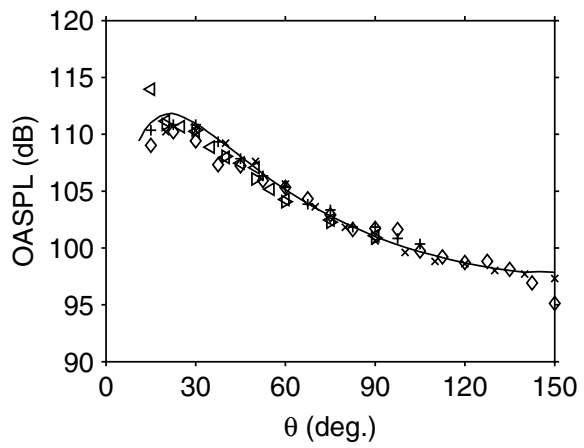

Figure 9: Directivity of overall sound pressure levels obtained at $52 D$ from the jet nozzle. (a) For the present jets at Mach numbers $\mathrm{M}_{\mathrm{j}}=0.6,0.75,0.9,0.98$, 1.1 and 1.6, from bottom to top. (b) For jets at $\mathrm{M}_{\mathrm{j}}=0.9$ : - present measurements, + Lush $[23,39], \diamond$ Tanna $[25,40], \triangleright$ Mollo-Christensen et al. [26], $\triangleleft$ Seiner et al. [42, 43], $\times$ SAE norm [44].

visible, whereas for $\theta>25^{\circ}$, the levels decrease monotonically with the angle, except for the jet at $\mathrm{M}_{\mathrm{j}}=1.1$. An increase of the sound levels in the upstream direction is indeed observed for this supersonic jet, which indicates the presence of high-magnitude screech tones. For the validation of the present far-field measurements, the sound levels obtained for the Mach number $M_{j}=0.9$ jet are compared in figure $9(b)$ to the corresponding experimental data of the literature [23, 25, 26, 39, 40, 42, 43, 44]. A very good agreement is observed.

The overall acoustic powers obtained for the jets are represented in figure 10 as a function of the Mach number $M_{j}$. These quantities are obtained by integrating the jet directivities, and are corrected to a jet area of $1 \mathrm{~m}^{2}$. The present results compare successfully with the experimental data of the literature. For the subsonic jets in particular, the variation of the power following the Lighthill $U_{j}^{8}$ law [3] is found.

As a final validation of the present measurements, the sound pressure spectra obtained at $\theta=30^{\circ}$ and $\theta=90^{\circ}$ for the $\mathrm{M}_{\mathrm{j}}=0.9$ jet are reported in figures 11(a) and 11(b). At $\theta=30^{\circ}$, the spectrum displays a well-marked peak at Strouhal number $\mathrm{St}=0.16$, whereas at $\theta=90^{\circ}$ the spectrum is more broadband with a peak for a higher Strouhal number $\mathrm{St}=0.3$. The modifications of the spectrum shape with the emission angle are usually connected to the presence of two components in subsonic jet noise [6, 26, 28]. The first component is characterized by a low-Strouhal-number contribution, and dominates for shallow radiation angles, whereas the second one is broadband, and is predominant in the sideline direction. The present narrowband spectra are also shown to be in good agreement with corresponding spectra of Tanna [40] and Jordan et al. [45]. The high-frequency components in Tanna's spectrum at $\theta=90^{\circ}$ are visibly overestimated, as it was recently mentioned by Viswanathan [46]. 


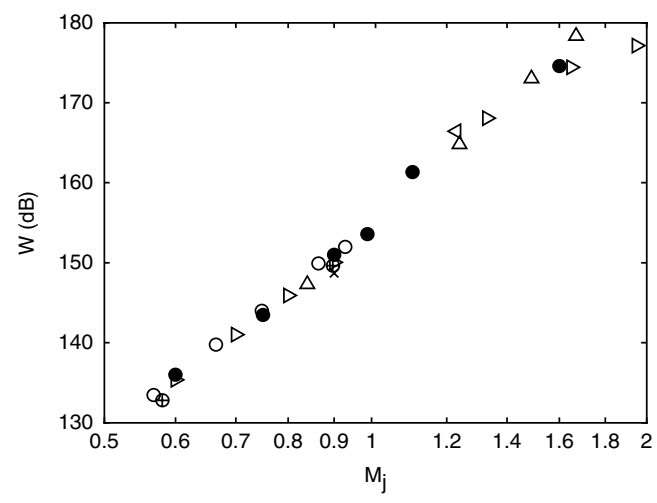

Figure 10: Overall acoustic power as a function of Mach number $M_{j}$, normalized for a jet area of $1 \mathrm{~m}^{2}$ : • present measurements, $\triangleleft \mathrm{Yu} \&$ Dosanjh [16], $\circ$ Lush [23, 39], $\triangleright$ Tanna [25, 40], $\times$ Stromberg et al. [41], $\triangle$ Seiner et al. $[42,43]$.

(a)

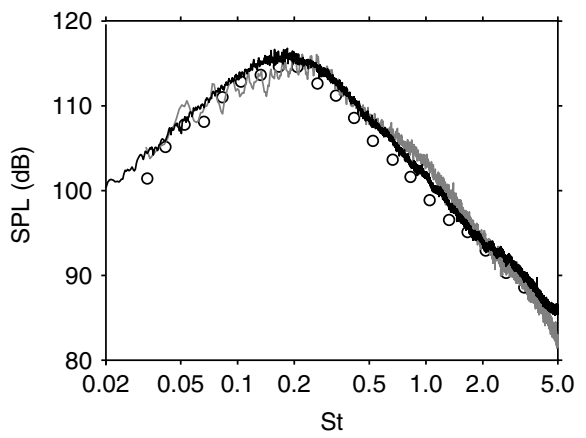

(b)

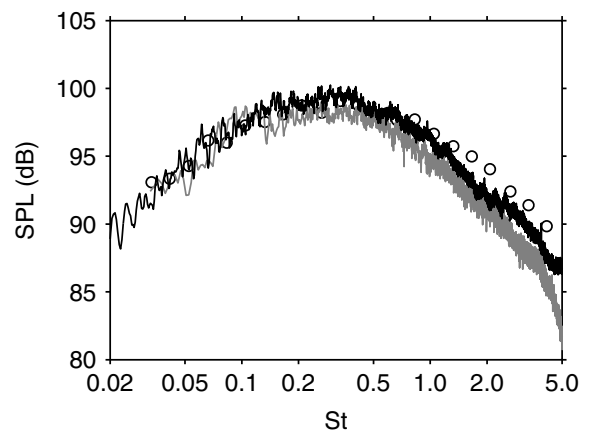

Figure 11: Sound pressure spectra obtained at $52 \mathrm{D}$ from the jet nozzle, (a) at $\theta=30^{\circ}$ and (b) at $\theta=90^{\circ}$, for jets at $\mathrm{M}_{\mathrm{j}}=0.9$ : — present measurements, ○ Tanna [40], _ Jordan et al. [45].

The pressure spectra are checked at different radiation angles. The spectra obtained for the jets at Mach numbers $\mathrm{M}_{\mathrm{j}}=0.6,0.9,1.1$ and 1.6 are thus represented in figure 12, for polar angles between $\theta=25^{\circ}$ and $90^{\circ}$ for the subsonic jets, and between $\theta=25^{\circ}$ and $140^{\circ}$ for the supersonic jets. The trends exhibited as the emission angle varies are the same as those exhibited by far-field experimental data of the literature [2, 3, 26]. The variations of the spectral properties for the subsonic jets are shown in figures 12(a) and 12(b). They are described just above within the comments of the spectra of the Mach 0.9 jet of figure 11. The spectra for the supersonic jets are given in figures 12(c) and 12(d). Similar behaviours are observed with respect to the near-field results of figure 5 : screech tones emerge and shock-associated noise appears, especially in the upstream direction 
(a)

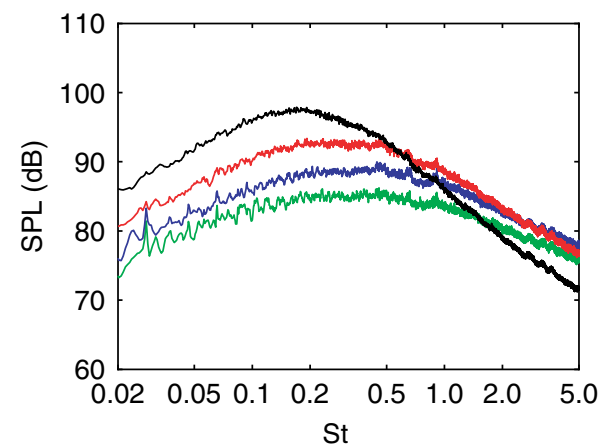

(c)

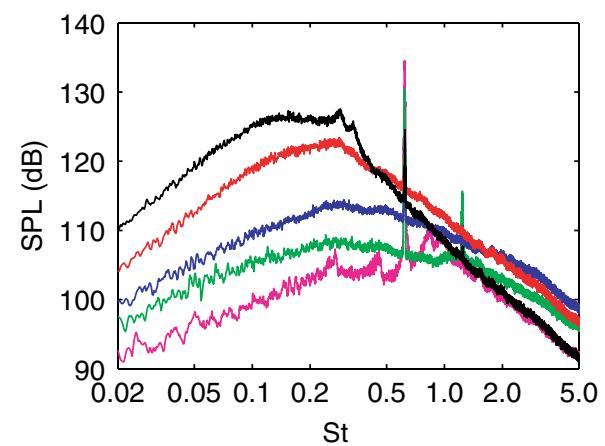

(b)

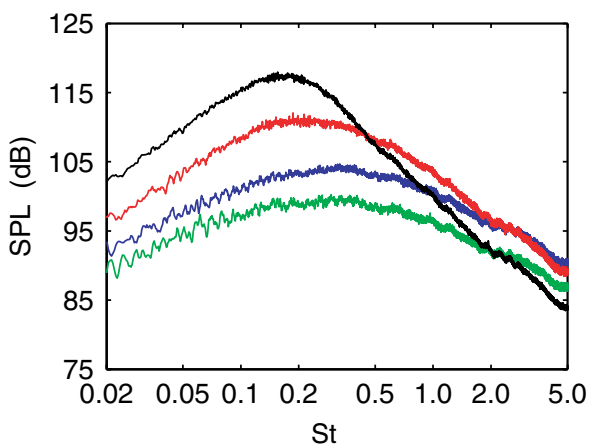

(d)

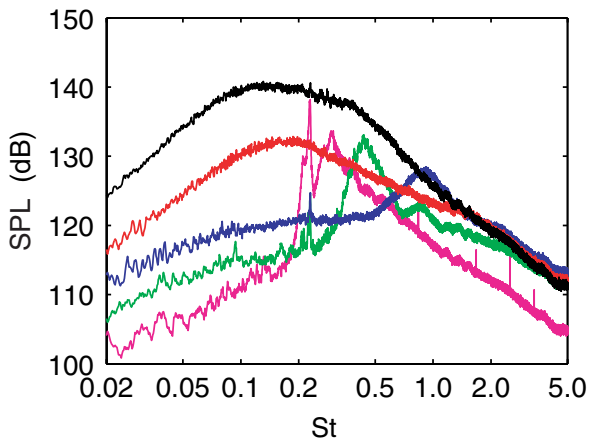

Figure 12: Sound pressure spectra obtained at 52D from the jet nozzle, $\longrightarrow$ at $\theta=25^{\circ}$, — at $\theta=40^{\circ}$, at $\theta=60^{\circ}$, — at $\theta=90^{\circ}$, and — at $\theta=140^{\circ}$. Jets at Mach numbers: (a) $\mathrm{M}_{\mathrm{j}}=0.6$, (b) $\mathrm{M}_{\mathrm{j}}=0.9$, (c) $\mathrm{M}_{\mathrm{j}}=1.1$, and (d) $\mathrm{M}_{\mathrm{j}}=1.6$.

at $\theta=140^{\circ}$ (magenta curves). The screech tones are also stronger for the Mach 1.1 jet, whereas shock-associated noise is particularly important for the Mach 1.6 jet.

The scaling of the levels of the far-field sound spectra with the jet velocity is now investigated for the subsonic isothermal jets. To deal with the two components of jet noise, the pressure spectra obtained at $\theta=25^{\circ}$ and at $\theta=90^{\circ}$ for the jets at $\mathrm{M}_{\mathrm{j}}=0.6,0.75$, 0.9 and 0.98 are represented in figures 13(a) and 13(b), with peaks that are collapsed using appropriate level scalings. The best results are observed using a $\left(U_{\mathrm{j}} / c_{\infty}\right)^{11}$ scaling at $\theta=25^{\circ}$, and a $\left(U_{\mathrm{j}} / c_{\infty}\right)^{7.5}$ scaling at $\theta=90^{\circ}$. Similar variations of the velocity exponent with the emission angle have been found in former experimental $[1,28]$ and numerical [6] studies. In these works, the peak levels at $\theta=90^{\circ}$ scale in particular also as $\left(U_{\mathrm{j}} / c_{\infty}\right)^{7.5}$.

The pressure spectra at $\theta=25^{\circ}$ and at $\theta=90^{\circ}$ for the four subsonic jets are represented in figures 14(a) and 14(b) with the aim of fitting their high-frequency parts. When they are plotted using a level scaling in $\left(U_{\mathrm{j}} / c_{\infty}\right)^{7}$, the spectra at both angles appear to collapse for Strouhal numbers $\mathrm{St} \geq 1$. In the downstream and sideline directions, the 
(a)

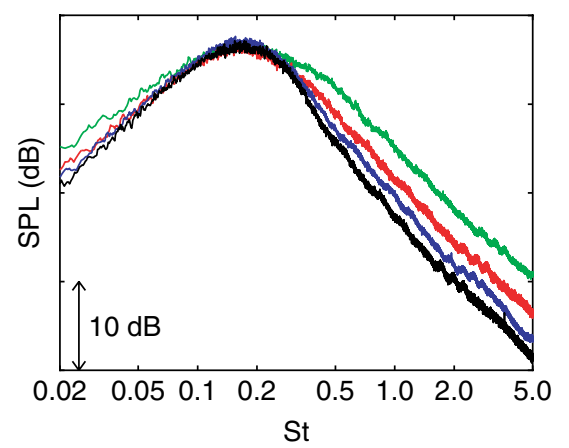

(b)

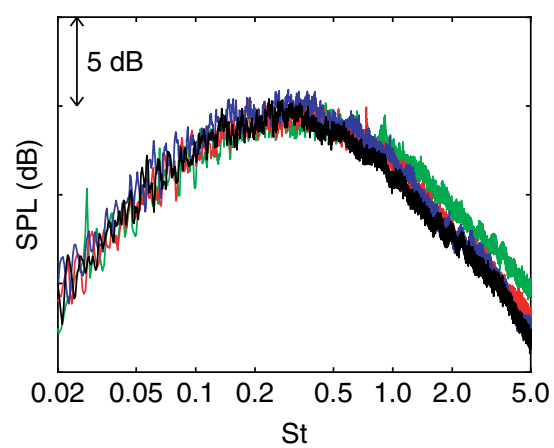

Figure 13: Sound pressure spectra obtained at $52 D$ from the jet nozzle, for the jets: $\longrightarrow$ at $\mathrm{M}_{\mathrm{j}}=0.6,-\mathrm{M}_{\mathrm{j}}=0.75,-\mathrm{M}_{\mathrm{j}}=0.9$ and $-\mathrm{M}_{\mathrm{j}}=0.98$; (a) at $\theta=25^{\circ}$ using a $\left(U_{\mathrm{j}} / c_{\infty}\right)^{11}$ scaling, (b) at $\theta=90^{\circ}$ using a $\left(U_{\mathrm{j}} / c_{\infty}\right)^{7.5}$ scaling.

(a)

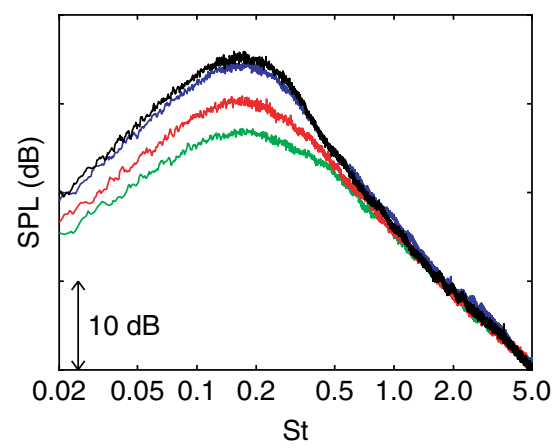

(b)

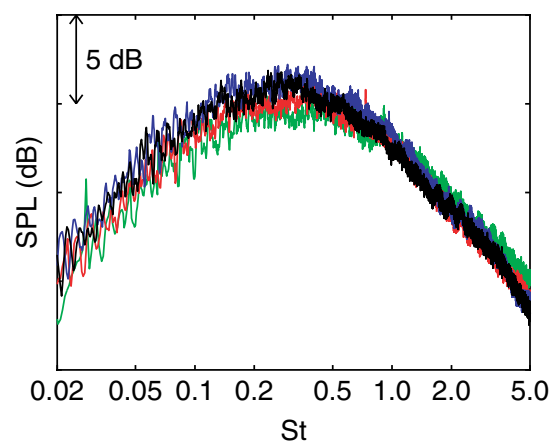

Figure 14: Sound pressure spectra obtained at $52 D$ from the jet nozzle, for the jets: - at $\mathrm{M}_{\mathrm{j}}=0.6,-\mathrm{M}_{\mathrm{j}}=0.75,-\mathrm{M}_{\mathrm{j}}=0.9$ and $-\mathrm{M}_{\mathrm{j}}=0.98$; (a) at $\theta=25^{\circ}$ and (b) $\theta=90^{\circ}$, using a $\left(U_{\mathrm{j}} / c_{\infty}\right)^{7}$ scaling.

same velocity exponent is therefore found for the high-frequency components of the radiated noise, and this exponent is different from those obtained for the peaks. Note that an identical result was noticed by Bogey et al. [6] for sound spectra provided by compressible Large-Eddy Simulations for subsonic jets at high Reynolds numbers. The spectra obtained in the downstream direction were indeed also found to collapse successfully for Strouhal numbers $\mathrm{St} \geq 0.8$ using a $\left(U_{\mathrm{j}} / c_{\infty}\right)^{7}$ scaling.

In figure 13 , the peak frequencies obtained at $\theta=25^{\circ}$ and at $\theta=90^{\circ}$ for subsonic jets visibly scale as the Strouhal number. Strouhal number scaling is well established for the angle of $90^{\circ}$, in particular by the results of various experiments $[1,23,24,25,26]$, but it is more confused for small angles of radiation. The frequency scaling of the noise spectra 
(a)

(1)

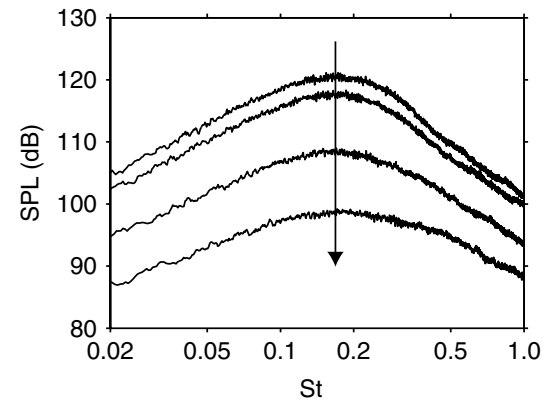

(2)

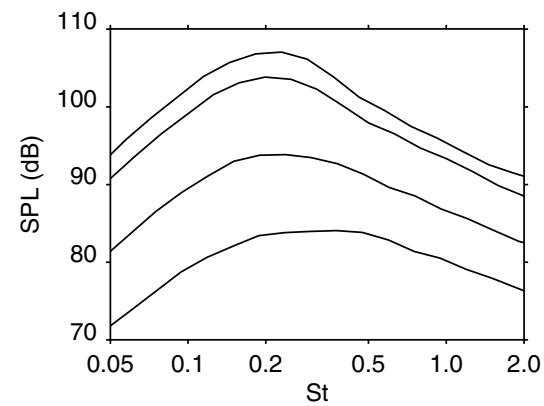

(b)
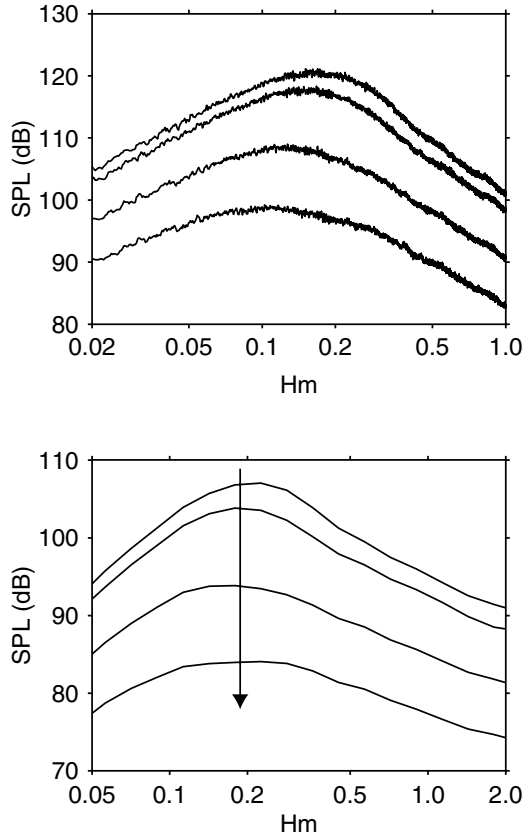

Figure 15: Sound pressure spectra obtained at $52 \mathrm{D}$ from the jet nozzle, at the angle of $\theta=25^{\circ}$ relative to the jet direction, for the jets at $\mathrm{M}_{\mathrm{j}}=0.6,0.75,0.9$ and 0.98 , from bottom to top. Representation: (1) in narrowband, (2) in 1/3-octave band; as a function of: (a) Strouhal number St $=f D / U_{\mathrm{j}}$, (b) Helmholtz number $\mathrm{Hm}=f D / c_{\infty}$.

is therefore now discussed using the present far-field data at $\theta=25^{\circ}$. Strouhal and Helmholtz number scalings are tested for narrow-banded and one-third octave spectra.

The narrow-banded pressure spectra obtained for the subsonic jets at $\theta=25^{\circ}$ are plotted as functions of the Strouhal number in figure 15(1.a), and as functions of the Helmholtz number in figure 15 (1.b). As already shown in figure 13(a), the peak frequencies are seen to be associated with a constant Strouhal number, in agreement with measurements [26] or numerical results [6]. The Helmholtz scaling appears therefore unappropriate.

The spectra are now represented using one-third octaves as functions of the Strouhal number in figure 15(2.a), and as functions of the Helmhotz number in figure 15(2.b). In this case, the spectra seem to scale as the Helmholtz number, as in reference experiments based on one-third octaves [23, 24, 25]. As previously noted by Zaman \& $\mathrm{Yu}$ [1], noise spectra obtained in the downstream direction exhibit equally well Strouhal scaling when narrow bands are used, and Helmholtz scaling when one-third octaves are considered. This artifact of the use of one-third octaves has to be kept in mind when 
features of the component responsible for the downstream jet noise are studied. The generation mechanism involved is indeed related to the jet velocity, contrary to what the Helmholtz scaling would imply.

\section{CONCLUSION}

The present paper reports characteristics of the noise radiated by cold and isothermal, high-speed round jets, obtained experimentally at the Centre Acoustique of Ecole Centrale de Lyon. It was motived by the need for accurate and unambiguous experimental data for the validation of jet noise prediction methods, especially for numerical simulation results, and for the modelling of jet noise sound sources. It hopefully complements measurements available in the literature. With this aim in view, near-field and far-field properties of jet noise are described in terms of levels and spectra. Their variations with the radiation angles, as well as sound source distributions, are found in good agreement with well-known features of jet noise. Scalings of the levels and peak frequencies of the sound spectra of subsonic jets are also discussed. The peak frequencies for small angles of radiation are in particular shown to scale as the Strouhal number when narrow-banded spectra are used.

\section{ACKNOWLEDGMENTS}

The second author is grateful to the Centre National d'Etudes Spatiales (CNES) for financial support. The authors also gratefully acknowledge P. Souchotte, J.-M. Perrin and P. Roland for the technical assistance during the experimental campaign.

\section{REFERENCES}

[1] Zaman, K.B.M.Q. and Yu, J.C., "Power spectral density of subsonic jet noise," J. Sound Vib., Vol. 98, No. 4, 1985, pp. 519-537.

[2] Tam, C.K.W., "Supersonic jet noise," Annu. Rev. Fluid Mech., Vol. 27, 1995, pp. 17-43.

[3] Tam, C.K.W., "Jet noise: since 1952," Theoret. Comput. Fluid Dynamics, Vol. 10, 1998, pp. 393-405.

[4] Wang, M., Freund J.B, and Lele, S.K. "Computational prediction of flowgenerated sound," Аnnu. Rev. Fluid. Mech., Vol. 38, 2006, pp. 483-512.

[5] Bogey, C., Bailly, C., and Juvé, D., "Noise investigation of a high subsonic, moderate Reynolds number jet using a compressible LES," Theoret. Comput. Fluid Dynamics, Vol. 16, No. 4, 2003, pp. 273-297.

[6] Bogey, C. and Bailly, C., "Investigation of downstream and sideline subsonic jet noise using Large Eddy Simulations," Theoret. Comput. Fluid Dynamics, Vol. 20, No. 1, 2006, pp. 23-40.

[7] Barré, S., Bogey, C., and Bailly, C., "Computation of the noise radiated by jets with laminar/turbulent nozzle-exit conditions," AIAA 2006-2443.

[8] Berland, J., Bogey, C., and Bailly, C., "Numerical study of screech generation in a planar supersonic jet," Phys. Fluids., Vol. 19, 2007, in press . 
[9] Viswanathan, K., "Jet aeroacoustic testing: issues and implications," AIAA Journal, Vol. 41, No. 9, 2003, pp. 1674-1689.

[10] Lyrintzis, A.S., "Surface integral methods in computational aeroacoustics-From the (CFD) near-field to the (Acoustic) far-field," International Journal of Aeroacoustics, Vol. 2, No. 2, 2003, pp. 95-128.

[11] Rahier, G., Prieur, J., Vuillot, F., Lupoglazoff, N., and Biancherin, A., "Investigation of integral surface formulations for acoustic predictions of hot jets starting from unsteady simulations," AIAA 2003-3164.

[12] Uzun, A., Lyrintzis, A.S., and Blaisdell, G.A., "Coupling of integral acoustics methods with LES for jet noise prediction," International Journal of Aeroacoustics, Vol. 3, No. 4, 2005, pp. 297-346.

[13] Andersson, N., Eriksson, L.-E., and Davidson, L., "Investigation of an isothermal Mach 0.75 jet and its radiated sound using large-eddy simulation and Kirchhoff surface integration," Int. J. Heat and Fluid Flow, Vol. 26, 2005, pp. 393-410.

[14] Brentner, K.S., "Analytical comparison of the acoustic analogy and Kirchhoff formulation for moving surfaces," AIAA Journal, Vol. 36, No. 8, 1998, pp. 1379-1386.

[15] Gloerfelt, X., Bailly, C., and Juvé, D., "Direct computation of the noise radiated by a subsonic cavity flow and application of integral methods," J. Sound Vib., Vol. 266, No. 1, 2003, pp. 119-146.

[16] Yu, J.C. and Dosanjh, D.S., "Noise field of a supersonic Mach 1.5 cold model jet," Journal of the Acoustical Society of America, Vol. 51, No. 5A, 1972, pp. 1400-1410.

[17] Troutt, T.R. and McLaughlin, D.K., "Experiments on the flow and acoustic properties of a moderate-Reynolds-number supersonic jet," J. Fluid Mech., Vol. 116, 1982, pp. 123-156.

[18] Zaman, K.B.M.Q., "Flow field and near and far sound field of a subsonic jet," J. Sound Vib., Vol. 106, No. 1, 1986, pp. 1-16.

[19] Ukeiley, L.S. and Ponton, M.K., "On the near field pressure of a transonic axisymmetric jet," International Journal of Aeroacoustics, Vol. 3, No. 1, 2004, pp. 43-66.

[20] Narayanan, S., Barber, T.J., and Polak, D.R., "High subsonic jet experiments: turbulence and noise generation studies," AIAA Journal, Vol. 40, No. 3, 2002, pp. 430-437.

[21] Arndt, R.E.A, Long, D.F., and Glauser, M.N., "The proper orthogonal decomposition of pressure fluctuations surrounding a turbulent jet," J. Fluid Mech., Vol. 340, 1997, pp. 1-33.

[22] Coiffet, F., Jordan, P., Delville, J., Gervais, Y., and Ricaud, F., "Coherent structures in subsonic jets: a quasi-irrotational source mechanism?," International Journal of Aeroacoustics, Vol. 5, No. 1, 2005, pp. 67-89.

[23] Lush, P.A., "Measurements of subsonic jet noise and comparison with theory," J. Fluid Mech., Vol. 46, No. 3, 1971, pp. 477-500. 
[24] Ahuja, K.K. and Bushell, K.W., “An experimental study of subsonic jet noise and comparison with theory," J. Sound Vib., Vol. 30, No. 3, 1973, pp. 317-341.

[25] Tanna, H.K., "An experimental study of jet noise. Part I: Turbulent mixing noise," J. Sound Vib., Vol. 50, No. 3, 1977, pp. 405-428.

[26] Mollo-Christensen, E., Kolpin, M.A., and Martucelli, J.R., "Experiments on jet flows and jet noise far-field spectra and directivity patterns," J. Fluid Mech., Vol. 18, 1964, pp. 285-301.

[27] Gaeta, R.J. and Ahuja, K.K., "Subtle differences in jet-noise scaling with narrowband spectra compared to 1/3-octave band," AIAA 2003-3124.

[28] Tam, C.K.W., Golebiowski, M., and Seiner, J.M., "On the two components of turbulent mixing noise from supersonic jets," AIAA 96-1716.

[29] Goldstein, M.E. and Leib, S.J., "The role of instability waves in predicting jet noise ," J. Fluid Mech., Vol. 525, 2005, pp. 37-72.

[30] Sunyach, M., Brunel, B., and G. Comte-Bellot, G., "Performances de la soufflerie anchoïqué a grande vitesse de l'Ecole centrale de Lyon," Revue d'Acoustique, Vol. 73, 1985, pp. 316-330.

[31] Zoppellari, E. and Juvé, D., "Reduction of jet noise by water injection," AIAA 97-1622.

[32] Zaman, K.B.M.Q., "Effect of the initial condition on subsonic jet noise," AIAA Journal, Vol. 23, No. 9, 1985, pp. 1370-1373.

[33] Bass, H.E., Sutherland, L.C., and Zuckerwar, A.J., "Atmospheric absorption of sound : Update," Journal of the Acoustical Society of America, Vol. 88, No. 4, 1990, pp. 2019-2021.

[34] Bass, H.E., Sutherland, L.C., Zuckerwar, A.J., Blackstock, D.T., and Hester, D.M., "Atmospheric absorption of sound : Further developments," Journal of the Acoustical Society of America, Vol. 97, No. 1, 1995, pp. 680-683.

[35] Raman, G., "Advances in understanding supersonic jet screech: review and perspective," Prog. Aerospace Sci., Vol. 34, 1998, pp. 45-106.

[36] Elias, G., "Experimental techniques for source location," Von Karman Institute for Fluid Dynamics, Lecture Series 1997-07, 1997.

[37] Zoppellari, E. and Juvé, D., "Reduction of hot supersonic jet noise by water injection," AIAA 98-2204.

[38] Bogey, C. and Bailly, C., "An analysis of the correlations between the turbulent flow and the sound pressure field of subsonic jets," to appear in J. Fluid Mech., 2007.

[39] Lush, P.A., "The generation and radiation of supersonic jet noise," Vol. V. Tech. Rep. AFAPT-TR-72-53, Air Force Aero Propulsion Laboratory, 1972.

[40] Tanna, H.K., "The generation and radiation of supersonic jet noise," Vol. III. Tech. Rep. AFAPL-TR-76-65, Air Force Aero Propulsion Laboratory, 1976.

[41] Stromberg, J.L., McLaughlin, D.K., and Troutt, T.R., "Flow field and acoustic properties of a Mach number 0.9 jet at a low Reynolds number," J. Sound. Vib., Vol. 72, No. 2, 1980, pp. 159-176. 
[42] Seiner, J.M., McLaughlin, D.K., and Liu, C.H., "Supersonic jet noise generated by largescale instabilities," Technical Paper 2072, NASA, 1972.

[43] Seiner, J.M. and Ponton, M.K., "Aeroacoustic data for high Reynolds number supersonic axisymmetric jets," NASA TM 86296, NASA, 1985.

[44] S.A.E., "Gas turbine exhaust noise prediction," Society for automotive engineers, Inc., ARP 876C, 1985.

[45] Jordan, P., Gervais, Y., Valiére, J.-C., and Foulon, H., "Final results from single point measurements," Project deliverable D3.4, JEAN - EU 5th Framework Programme, G4RDCT2000-00313, 2002.

[46] Viswanathan, K., "Aeroacoustics of hot jets," J. Fluid Mech., Vol. 516, 2004, pp. 39-82. 